\title{
Experimental analysis of the size effect on the compressive behaviour of cylindrical samples core-drilled from existing brick masonry
}

Jorge Segura ${ }^{\mathrm{a}, *}$, Luca Pelà ${ }^{\mathrm{a}}$, Pere Roca ${ }^{\mathrm{a}}$, Albert Cabané ${ }^{\mathrm{a}}$

${ }^{a}$ Department of Civil and Environmental Engineering, Universitat Politècnica de Catalunya (UPCBarcelonaTech), 08034 Barcelona, Spain

* Corresponding author. Department of Civil and Environmental Engineering, Universitat Politècnica de Catalunya (UPC-BarcelonaTech), Jordi Girona 1-3, 08034 Barcelona, Spain. E-mail address: jorge.segura@upc.edu

Abstract: This paper presents the results of an experimental programme about the evaluation of the size effect on the compressive behaviour of cylindrical samples of existing masonry. The study focuses on the in-situ coring and experimental testing of core specimens with $150 \mathrm{~mm}$ and $90 \mathrm{~mm}$ diameter. The $150 \mathrm{~mm}$ cylinder, recurrent in minor destructive evaluation of the compressive strength of existing masonry, includes four brick pieces, two mortar beds and one head joint. The $90 \mathrm{~mm}$ specimen includes one mortar bed and two segments of brick, and inflicts less damage on the inspected structural member due to its lower invasivity. The experimental research investigates the size effect on four different types of clay brick masonry. The first type was built in the laboratory using historicallike materials. The other three types of masonry belong to structural walls of existing historical buildings. The combination of experimental results from laboratory controlled materials and existing historical members shows that the size of the cylindrical specimen has regular effect on the compressive strength and the Young's modulus. The consistent relationship found between the compressive strengths of the $150 \mathrm{~mm}$ and $90 \mathrm{~mm}$ core samples allows the use of the latter specimen for a more respectful inspection of existing structural masonry. 
Keywords: MDT; core drilling; in-situ sampling; masonry; clay brick; lime mortar; compressive strength; Young's modulus; size effect; historical buildings.

\section{Highlights:}

Compression tests on brick masonry cylinders of $150 \mathrm{~mm}$ and $90 \mathrm{~mm}$ are presented.

Results from laboratory controlled and real historical materials are compared.

The average ratio between the compressive strengths of $150 \mathrm{~mm}$ and $90 \mathrm{~mm}$ cores is 0.75 .

The average ratio between the Young's moduli of $150 \mathrm{~mm}$ and $90 \mathrm{~mm}$ cores is 0.85 .

Testing $90 \mathrm{~mm}$ cylinders is found to be an alternative for inspecting existing masonry.

\section{Nomenclature}

CV coefficient of variation

E Young's modulus of masonry (generic)

$E_{150 \mathrm{~mm}}$ Young's modulus of masonry obtained through tests on $150 \mathrm{~mm}$ cylinders

$E_{90 \mathrm{~mm}}$ Young's modulus of masonry obtained through tests on $90 \mathrm{~mm}$ cylinders

$f_{b} \quad$ normalized compressive strength of bricks

$f_{c} \quad$ compressive strength of masonry (generic)

$f_{c, 150 \mathrm{~mm}}$ compressive strength of masonry obtained through tests on $150 \mathrm{~mm}$ cylinders

$f_{c, 90 \mathrm{~mm}}$ compressive strength of masonry obtained through tests on $90 \mathrm{~mm}$ cylinders

$f_{c}^{*} \quad$ compressive strength of masonry derived from the proposed experimental approach

$f_{c, A C I} \quad$ estimation of the compressive strength of masonry with ACI expression

$f_{c, E C 6}$ estimation of the compressive strength of masonry with Eurocode 6 expression

$f_{m, D P T} \quad$ compressive strength of mortar obtained through double punch tests

MDT minor destructive testing technique

$R_{c} \quad$ strengths ratio, computed as $f_{c, 150 \mathrm{~mm}} / f_{c, 90 \mathrm{~mm}}$

$R_{E} \quad$ Young's moduli ratio, computed as $E_{150 \mathrm{~mm}} / E_{90 \mathrm{~mm}}$

$r^{2} \quad$ coefficient of determination

$\Delta \%$ difference in percentage between experimental and empirical estimations 


\section{Introduction}

The use of masonry as building material is abundant all over the world, including many major examples of architectural heritage. Many of these buildings are in need of structural assessment because of structural damage or material decay experienced over the years. Additionally, their structural condition often requires careful evaluations due to the adaptation to new uses. The knowledge on the mechanical behaviour of this material and its most influent parameters, such as compressive strength and Young's modulus, is of paramount importance for this kind of structural evaluations.

The experimental determination of the mechanical properties of existing masonry is a challenging task. The in-situ sampling and subsequent testing of masonry specimens in the laboratory provide a suitable approach to the problem, since it is possible to obtain direct measurements of the mechanical parameters that describe the elastic and strength behaviour. However, the composite character of masonry requires laboratory tests on sufficiently large samples, able to represent the complexity of the material texture, and therefore including both units and mortar joints. Yet, the insitu sampling of large prismatic specimens of masonry, e.g. extracted from existing walls, may encounter important difficulties. In addition, sampling procedures should always be minimal in the case of historical buildings due to their cultural heritage value.

A possible solution to the aforementioned limitations in the case of brickwork is offered by the minor destructive testing (MDT) technique consisting in extracting masonry core samples from the existing structure to be tested in the laboratory. This technique was proposed by the UIC Leaflet [1] on the inspection of brick masonry arch bridges, which suggests to core drill cylinders with a diameter of at least $150 \mathrm{~mm}$ including four brick segments, two mortar beds and one head joint. The cylindrical specimen is then tested under compression along the direction perpendicular to the mortar beds. Recent researches have shown that tests on such samples are able to reproduce the complex failure 
mechanisms of brickwork in compression. The calibration of this technique by comparison with tests on other non-standard [2-4] and standard [5-7] masonry specimens has shown its ability to provide reliable estimations of the compressive strength of the material. Pelà et al. [6] investigated also the possibility of estimating the Young's modulus of masonry by means of compression tests on this type of specimen.

The use of cylindrical samples smaller than those suggested by the UIC Leaflet might constitute a possible alternative to reduce the damage inflicted to the building. This may reveal to be necessary in case of protected heritage constructions requiring minimum invasivity of the in-situ inspection. The use of smaller cylinders may provide also additional practical advantages, besides the reduction of damage grade during sampling. A larger amount of cylindrical cores could be extracted, allowing an increase of the statistical significance of the results. Also, finding convenient spots where to drill smaller cores is easier than for $150 \mathrm{~mm}$ diameter cylinders, especially in the case of plastered walls. Moreover, the reduced size of the cores makes the transport, storage and testing operations easier.

A suitable cylindrical sample with dimensions smaller than the $150 \mathrm{~mm}$ diameter specimen of the UIC Leaflet should still include both the brick and mortar components in order to be able to represent realistically the composite character of the masonry material. The smallest core sample with these characteristics is composed of one diametric mortar joint and two cylindrical segments of brick. The diameter of this type of specimen should be around $90 \mathrm{~mm}$ and $100 \mathrm{~mm}$ in order to ensure a proper cutting of the two bricks without affecting the integrity of the interposed mortar joint. The use of cylinders with a diameter of $100 \mathrm{~mm}$ to determine the masonry compression parameters has been already investigated in $[8,9]$ with satisfactory results.

Previous experimental and analytical studies available in the scientific literature have already addressed the size dependence on the strength of different types of brick masonry samples. The research by Carpinteri et al. [10] focused on size dependence on fracture properties, such as strength and toughness, by testing different samples under three-point bending. The authors highlighted the 
important effect of constitutive heterogeneity on the size effect, especially when the specimen size is small. The numerical study by Lourenço [11] also showed the effect on tensile and compressive failures of the geometrical relationship between masonry units and the structural size.

This paper presents an experimental research aimed at evaluating the size effect on the compressive strength and elasticity of cylindrical samples of existing brick masonry of $150 \mathrm{~mm}$ and $90 \mathrm{~mm}$ diameter. The adequacy of the $150 \mathrm{~mm}$ diameter masonry cores to assess the mechanical behaviour of masonry in compression has been already investigated and validated in [2-7]. This research pays special attention to the use of the smaller $90 \mathrm{~mm}$ diameter core samples, with the following specific objectives: (1) exploring the possibility to reproduce the mechanical behaviour of brick masonry in compression by means of tests carried out on them; (2) analysing the consistency and reliability of the results obtained and, specifically, investigating whether the scattering obtained is sufficiently moderate; (3) determining size-effect correlations for compressive strength and Young's modulus based on the comparison with experimental results obtained from the $150 \mathrm{~mm}$ diameter cylinders.

The comparison between the tests on the two types of cylindrical cores has been carried out for four different types of masonry, all of them made of solid clay bricks and lime mortar but characterized by different brick and mortar compressive strengths.

The paper includes five sections. After an introduction about the purpose and objectives of the study, Section 2 presents the first experimental campaign performed on masonry walls built in the laboratory with historical-like materials. The extraction, preparation and testing of two sets of cylinders, with $90 \mathrm{~mm}$ and $150 \mathrm{~mm}$ diameter, were carried out in a laboratory controlled environment. Section 3 presents a second stage of the research, with three different experimental campaigns on different masonry typologies obtained from three real existing buildings. All field campaigns considered the in-situ sampling and subsequent laboratory testing of $90 \mathrm{~mm}$ and $150 \mathrm{~mm}$ cylindrical specimens. The results from the experimental programmes are discussed in Section 4, in terms of 
failure modes, stability of experimental measurements, and size effect correlations of the compressive strengths and Young's moduli of the $90 \mathrm{~mm}$ and $150 \mathrm{~mm}$ core samples. Section 4 presents also a comparison with predictive expressions from building codes. The paper ends with the concluding Section 5.

\section{Experimental programme on masonry built in the laboratory}

The first stage of the research considered core samples extracted from masonry walls built in the laboratory with historical-like material components. The samples of this campaign were identified with code "MA". The experimental programme was carried out at the Laboratory of Technology of Structures and Building Materials of the Technical University of Catalonia (UPC - BarcelonaTech).

\subsection{Materials and construction of walls}

As stated before, the proposed MDT technique aims to study the compressive behaviour of existing brick masonry structures, with special focus on the case of historical buildings. Therefore, the masonry built in the laboratory was designed to represent as much as possible a typical historical masonry with solid clay bricks and low-strength lime mortar in joints.

The bricks were handmade and presented rough surfaces and slightly variable dimensions. The nominal dimensions were $305 \times 145 \times 45 \mathrm{~mm}^{3}$. A set of bricks was polished and cut into pieces of dimensions $100 \times 100 \mathrm{~mm}^{2}$ to be tested in compression according to EN 772-1 [12]. Table 1 reports the normalized compressive strength $\left(f_{b}\right)$, obtained by multiplying the experimental value by the shape factor proposed by the standard.

Two single-leaf walls with dimensions $1.6 \times 0.8 \times 0.145 \mathrm{~m}^{3}$ were built in the laboratory by using the aforementioned bricks (Fig. 1a). A qualified mason built the walls in running bond using a pure aerial lime mortar, classified as CL90 according to EN 459-1 [13]. The joint thickness varied between $15 \mathrm{~mm}$ and $20 \mathrm{~mm}$. The walls were stored in laboratory conditions for more than one year 
until the coring process. This long time was necessary for a sufficient hardening of the aerial lime mortar.

At the time of the coring process for obtaining the masonry cylinders, some mortar joints were dismantled. These portions of mortar were cut into slabs with approximate dimensions of $50 \times 50 \mathrm{~mm}^{2}$. After regularization with a little amount of gypsum powder, these pieces were subjected to the double punch test (DPT) by following DIN 18555-9 [14]. More detailed information on DPT can be found in [15-17]. As can be seen in Table 1, the average compressive strength value measured by means of this test $\left(f_{m, D P T}\right)$ was equal to $1.61 \mathrm{MPa}$. It is worth mentioning that this compressive strength value for the aerial lime mortar was obtained after two years from the construction of the wall. The DPT technique, suitable for the mechanical characterisation of the mortar joints in existing buildings, was considered in campaign "MA" as well as in the three case studies that will be described in Section 3. The DPT results from the four campaigns will allow direct comparisons of the actual compressive strength of mortar inside the joints.

Table 1. Experimental compressive strength of bricks $\left(f_{b}\right)$ and mortar joints $\left(f_{m, D P T}\right)$ in campaign "MA" executed on masonry built in the laboratory.

\begin{tabular}{ccc}
\hline "MA" & $f_{b}$ & $f_{m_{-} D P T}$ \\
\hline Average (MPa) & 17.44 & 1.61 \\
Number of specimens & 14 & 32 \\
$\mathrm{CV}$ & $8.3 \%$ & $20.1 \%$ \\
\hline
\end{tabular}

\subsection{Core drilling and preparation of masonry specimens}

Before the extraction of masonry cylindrical samples, a low vertical compression was applied to the walls with the aim of ascertaining their stability during the transportation inside the laboratory and the coring process.

The extraction of the cores was done by horizontal drilling using the dry coring technology proposed, among others, in [4] and [6]. Two types of cylinders were extracted (Fig. 1b). First, $150 \mathrm{~mm}$ diameter core samples (actual diameter of $152.5 \mathrm{~mm}$ ), including one vertical and two horizontal mortar 
joints and four brick portions. Second, $90 \mathrm{~mm}$ diameter core samples (actual diameter of $92 \mathrm{~mm}$ ), including a single diametric mortar joint and two brick portions. All the cores had an approximate depth of $145 \mathrm{~mm}$. Six cylindrical specimens of each diameter were extracted from the walls. Additional cores were extracted and used for other parallel researches carried out by the authors [16].
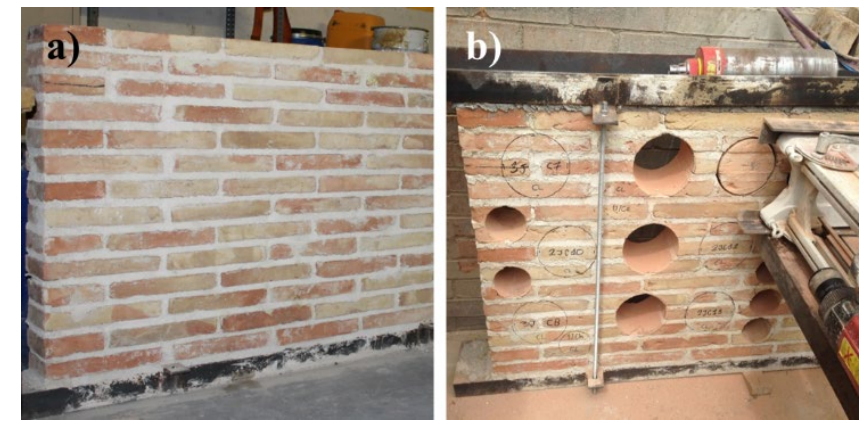

Fig. 1. a) Masonry wall built in the laboratory for the campaign "MA", and b) core drilling of $150 \mathrm{~mm}$ and $90 \mathrm{~mm}$ cylindrical samples.

After extraction, two high strength mortar caps were casted on the cylindrical specimens (Fig. 2). These caps were used to create two flat surfaces allowing the application of an evenly distributed load. This approach was already proposed in [5-7] and differs from the UIC leaflet [1] where it is recommended to apply the load through steel concave loading plates and to make use of lead sheets in contact with the sample. The high strength mortar caps match the irregular curved perimeter of the cores and avoid any stress concentration during the tests. The widths of the caps were about $110 \mathrm{~mm}$ for the $150 \mathrm{~mm}$ cores, and about $70 \mathrm{~mm}$ for the $90 \mathrm{~mm}$ cores. These dimensions were chosen to maintain similar width to diameter ratios for the two different types of cylinder. 

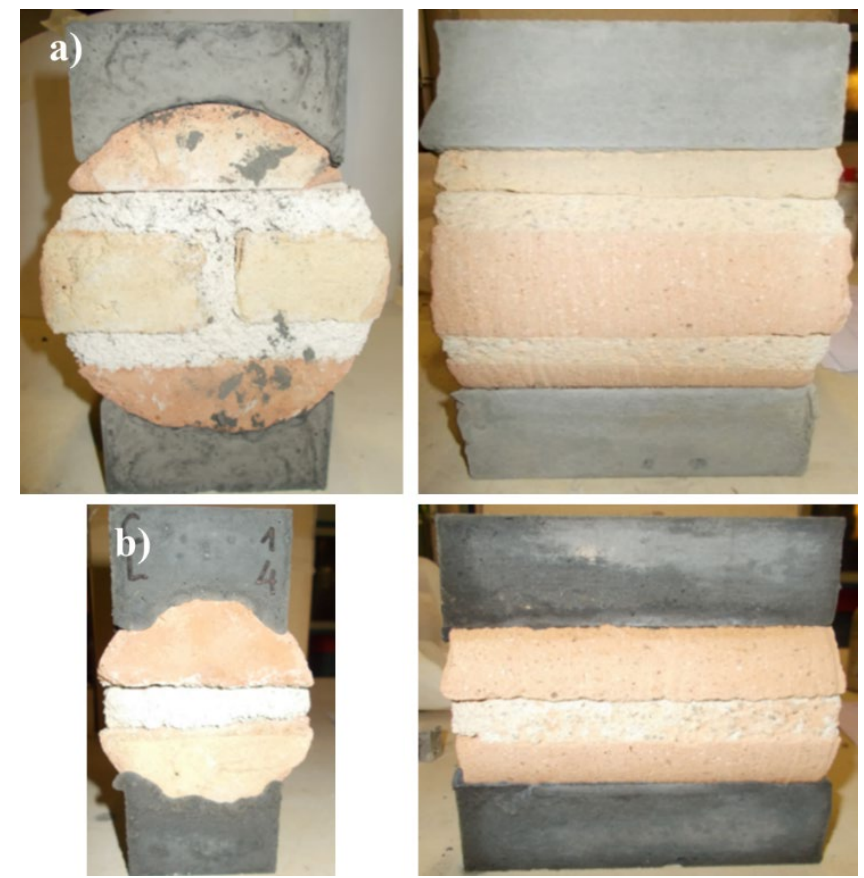

Fig. 2. Front and lateral views of regularized core samples of campaign "MA": a) 150 mm cylinder and b) 90 mm cylinder.

\subsection{Testing procedures}

Both $150 \mathrm{~mm}$ and $90 \mathrm{~mm}$ cores were tested in a general-purpose compression machine with load capacity of $3000 \mathrm{kN}$ (Fig. 3) after two years from the construction of the walls. Thanks to the mortar caps, uniaxial compression could be applied perpendicularly to the horizontal joints.

The tests were carried out in two consecutive stages. The first one was aimed to study the elastic behaviour of the material and consisted in the application of three loading/unloading cycles under load control. These cycles ranged from $5 \%$ to $20 \%$ of a supposed maximum load that had been estimated before the tests. In the lack of a specific standard for these tests, the first stage was planned taking as reference some standards on the measurement of the Young's modulus for other materials [18-21], as well as former researches [6,22]. The Young's modulus was calculated for the loading branch of the third cycle. The second stage aimed to investigate the nonlinear behaviour of the material and to measure its compressive strength. The cylinders were tested under displacement control, at a rate of $0.004 \mathrm{~mm} / \mathrm{s}$. The tests were stopped after registering part of the post-peak softening response. 
Linear variable differential transformers (LVDTs) were used to record the displacements experienced during the tests. Two vertical LVDTs of $\pm 5 \mathrm{~mm}$ range and $5 \mu \mathrm{m}$ precision were attached to the mortar caps to capture the vertical displacements. The vertical strains in compression were calculated as the ratio of the displacement experienced by the LVDTs and the cylinder's diameter, as the high strength mortar caps had negligible deformation in comparison with that of the masonry.
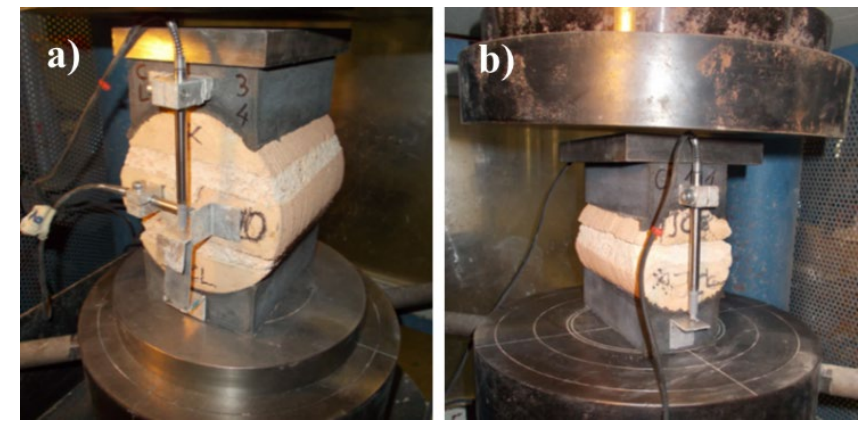

Fig. 3. Experimental setups of campaign "MA" for a) $150 \mathrm{~mm}$ cylinder and b) $90 \mathrm{~mm}$ cylinder.

\subsection{Results}

Fig. 4 shows the stress-strain curves obtained during the second stage for the $150 \mathrm{~mm}$ and 90 mm cylindrical samples. All the curves present an initial linear branch. The end of this branch corresponds to the maximum stress reached in the previous loading/unloading cycles. After that, all the specimens present another linear branch with lower slope.

In the case of the $150 \mathrm{~mm}$ core samples (Fig. 4a), the linear branch continues up to $80 \div 90 \%$ of the maximum load, when a sudden reduction is registered in the slope for the majority of the specimens. This point usually corresponds to the appearance of the first crack, and indicates the start of a noticeable nonlinear behaviour until the peak stress. Then, a softening response follows with decreasing stresses under increasing strains. The curves of the $90 \mathrm{~mm}$ core samples (Fig. $\mathbf{4 b}$ ) are similar. However, the nonlinear behaviour before the failure begins at an earlier point corresponding to $50 \div 60 \%$ of the maximum load. The softening is more accentuated, showing a faster loss of loadcarrying capacity under increasing strains. 

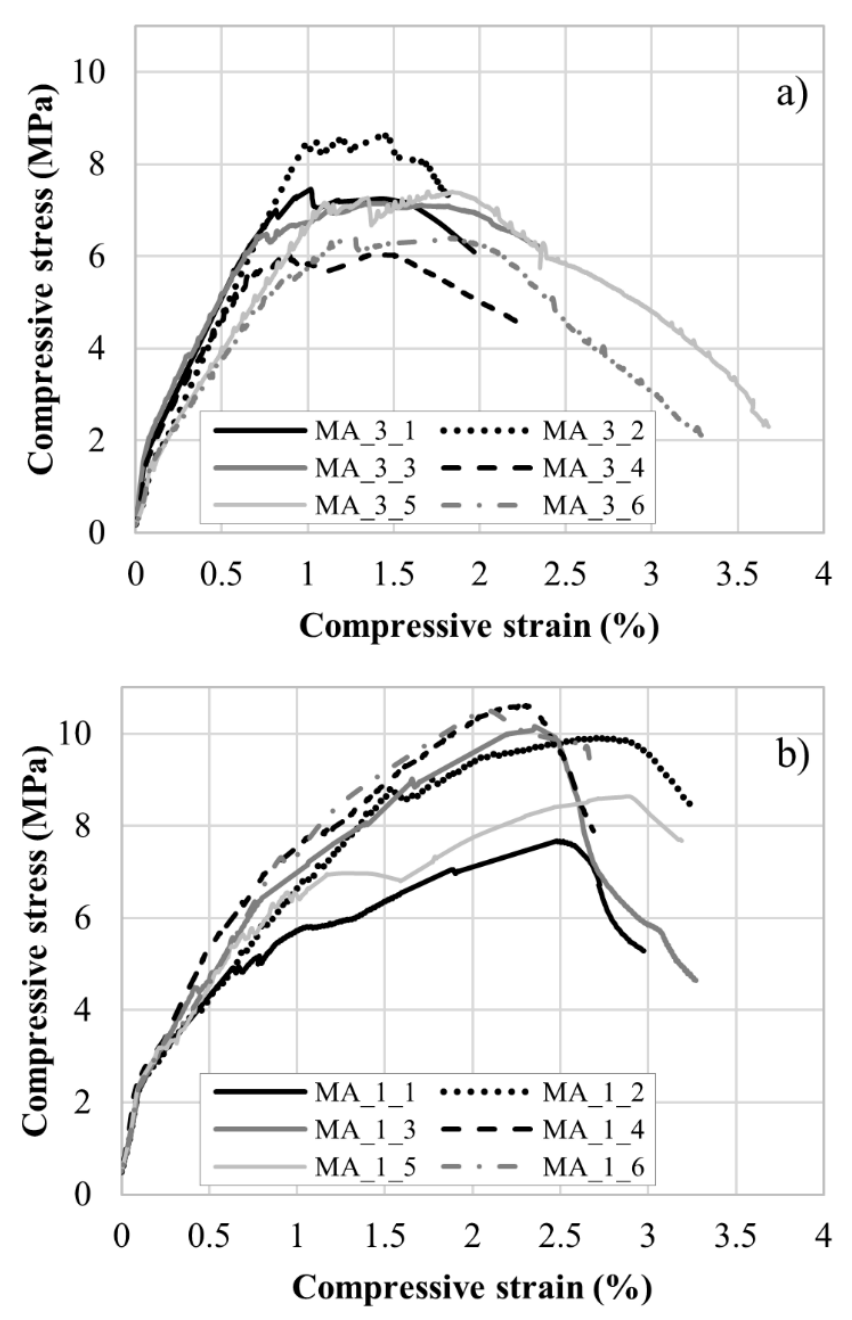

Fig. 4. Compressive stress-strain curves of core samples of campaign "MA": a) $150 \mathrm{~mm}$ cylinders and b) $90 \mathrm{~mm}$ cylinders.

The failure mechanism observed in the $150 \mathrm{~mm}$ core samples started with a crack arising next to one of the edges of the mortar caps, either within the top or bottom brick of the specimen (Fig. 5a). The crack first appeared at one side of the specimen, possibly corresponding to the weakest of the two bricks. With increasing load, this crack propagated further by splitting the intermediate brick, and then a symmetrical crack appeared at the other lateral side (Fig. 5b). Additional distributed thinner vertical cracks appeared through the entire specimen, both at the front and rear faces, as well as on the lateral faces. At failure (Fig. 5c), the two main cracks developed also through the mortar until fully connecting the top and bottom caps. This caused the detachment of the external parts, with a characteristic sandglass shape failure. 

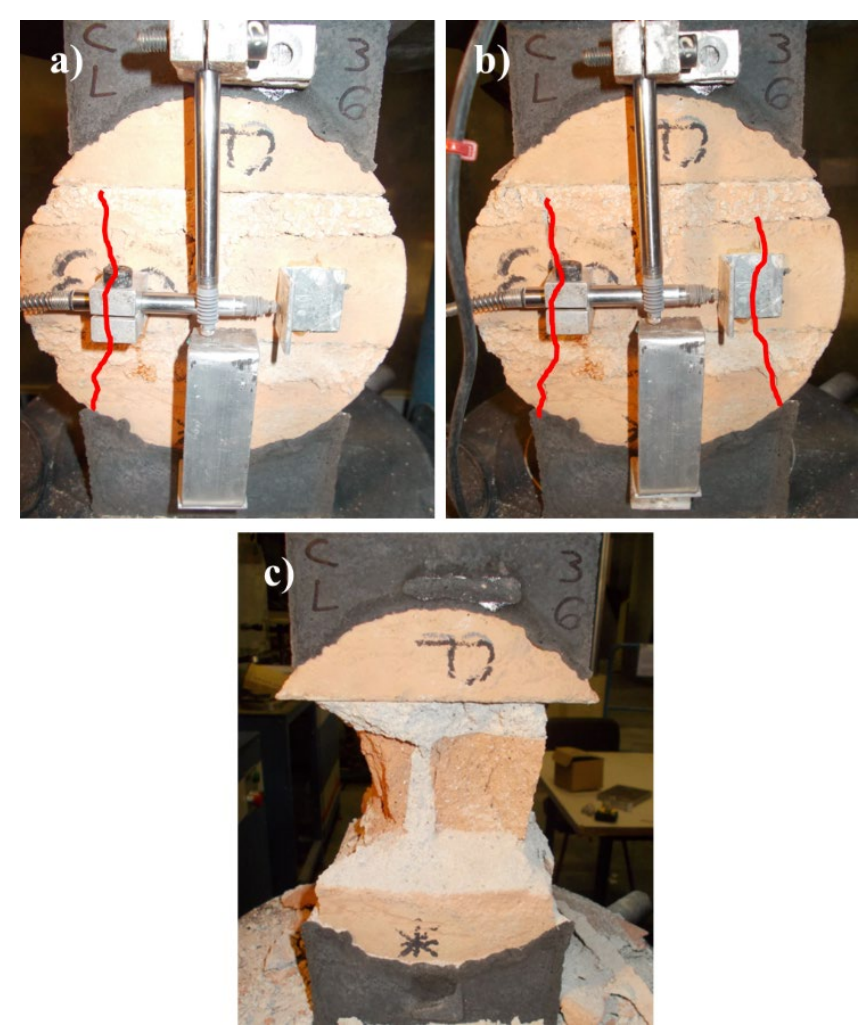

Fig. 5. Typical failure of $150 \mathrm{~mm}$ cylinders in compression tests of campaign "MA": a) appearance of the first crack at one side, b) further opening of the first crack and development of a second crack at the other side, and c) final sandglass failure.

The cracking process was similar in the $90 \mathrm{~mm}$ cylinders (Fig. 6a). The first initial vertical crack appeared in one of the two bricks, near the cap edge. A second crack appeared either in the same brick near the opposite edge or in the other brick by creating a longer crack at the same side. The lateral vertical cracks propagated also through the diametric mortar joint. At failure (Fig. 6b), the lateral cracks crossed the entire specimen from the top to the bottom caps causing the detachment of the external parts and the sandglass shape failure. Additional thinner vertical cracks appeared at the midsection of the bricks. 



Fig. 6. Typical failure of $90 \mathrm{~mm}$ cylinders in compression tests of campaign "MA": a) vertical cracks crossing the core from the top to the bottom mortar caps, and b) final sandglass failure.

As described above, a similar failure mode was obtained for both $150 \mathrm{~mm}$ and $90 \mathrm{~mm}$ cylinders, producing a sandglass shaped remaining core. At the peak load, the external parts of the cylinders were already separated from the central core by vertical cracks. This suggests that the effective resisting cross-section at failure corresponded to the width of the mortar caps. Taking into account this mechanical response, the compressive stresses acting on the specimen were calculated as the ratio between the load and the cross section determined by the width of the mortar caps. This is in agreement with the findings of $[5,7,23]$. Table 2 presents the summary of the experimental results of campaign "MA", including the compressive strength $\left(f_{c}\right)$ and the Young's modulus $(E)$ of masonry.

Table 2. Compressive strength $\left(f_{c}\right)$ and Young's modulus $(E)$ of $150 \mathrm{~mm}$ and $90 \mathrm{~mm}$ masonry cylinders in campaign "MA".

\begin{tabular}{cccccc}
\hline \multicolumn{2}{c}{ "MA" 150 mm cylinders } & \multicolumn{3}{c}{ "MA" 90 mm cylinders } \\
\hline ID & $\begin{array}{c}f_{c, 150 \mathrm{~mm}} \\
(\mathrm{MPa})\end{array}$ & $\begin{array}{c}E_{150 \mathrm{~mm}} \\
(\mathrm{MPa})\end{array}$ & ID & $\begin{array}{c}f_{c, 90 \mathrm{~mm}} \\
(\mathrm{MPa})\end{array}$ & $\begin{array}{c}E_{90 \mathrm{~mm}} \\
(\mathrm{MPa})\end{array}$ \\
\hline MA_3_1 & 7.46 & -- & MA_1_1 & 7.67 & 1771 \\
MA_3_2 & 8.64 & 1328 & MA_1_2 & 9.93 & 1739 \\
MA_3_3 & 7.15 & -- & MA_1_3 & 10.16 & 1806 \\
MA_3_4 & 6.05 & 1900 & MA_1_4 & 10.62 & 2253 \\
MA_3_5 & 7.41 & 1282 & MA_1_5 & 8.63 & 1863 \\
MA_3_6 & 6.45 & 1390 & MA_1_6 & 10.51 & 1823 \\
\hline Average & 7.19 & 1475 & Average & 9.59 & 1876 \\
CV & $12.5 \%$ & $19.4 \%$ & CV & $12.3 \%$ & $10.1 \%$ \\
\hline
\end{tabular}

The values of compressive strength obtained from the $150 \mathrm{~mm}$ samples are lower than those from the $90 \mathrm{~mm}$ cylinders. The average $f_{c}$ values are equal to 7.19 $\mathrm{MPa}$ and $9.59 \mathrm{MPa}$ respectively. 
This is a direct consequence of the size effect related to the two different geometries. The strength of the $150 \mathrm{~mm}$ samples is particularly affected by the presence of two mortar beds and the central head joint. The ratio between the strengths of the $150 \mathrm{~mm}$ and $90 \mathrm{~mm}$ samples is 0.75 . The scattering obtained in the measurement of the compressive strength is very similar in the two types of cylinders, with a coefficient of variation around $12 \%$. This scattering can be considered moderate taking into account the nature of the historical-like masonry investigated and the fact that it is built with handmade bricks. It is interesting to note that, in spite of their smaller size, the use of the $90 \mathrm{~mm}$ samples has not increased the scattering of the results with respect to that of the $150 \mathrm{~mm}$.

The value of the Young's modulus obtained from the $150 \mathrm{~mm}$ samples is also lower than that estimated from the $90 \mathrm{~mm}$ specimens. In specific, $E$ is equal to $1475 \mathrm{MPa}$ and $1876 \mathrm{MPa}$ respectively. This can be explained partly by the different size of the samples and also by the presence of two mortar beds in the $150 \mathrm{~mm}$ core. The ratio between the Young's moduli of the $150 \mathrm{~mm}$ and $90 \mathrm{~mm}$ samples is 0.79 . The coefficient of variation is almost $20 \%$ in the case of the $150 \mathrm{~mm}$ specimens, which is still acceptable for the type of masonry tested. Again, the low scattering found for the tests of the $90 \mathrm{~mm}$ cylinders (CV 10\%) confirms that the use of a smaller diameter is not introducing significant sources of variability.

The ratios relating the Young's modulus to the compressive strength $\left(E / f_{c}\right)$ are also very similar for the two types of specimen. They are equal to 214 for the $150 \mathrm{~mm}$ samples, and 198 for the $90 \mathrm{~mm}$ ones.

\section{Experimental programmes on existing masonry buildings}

This section presents three experimental campaigns on real case studies intended to provide more results about the size effect on the masonry compression parameters for $90 \mathrm{~mm}$ and $150 \mathrm{~mm}$ core samples. Three different examples of urban architecture of Barcelona, Spain, were inspected in the 
context of on-going renovation works. In all cases, samples of constituents (bricks and mortar joints), and cylinders (90 $\mathrm{mm}$ and $150 \mathrm{~mm}$ cores) were extracted and then tested in the Laboratory of Technology of Structures and Building Materials of the Technical University of Catalonia (UPC BarcelonaTech).

The campaign with code "MB" dealt with one emblematic example of Catalonian industrial heritage (Fig. 7a), namely the textile factory "Fabra i Coats" built in 1910-1920 in Barcelona. The main 4-storey building consists of floors made of steel beams with small ceramic vaults in between supported by load bearing masonry walls. Its industrial activity decayed during the 1970 s and the municipality recently converted the complex into a new cultural facility. Some works refurbished the building and adapted it to hold public exhibitions according to modern regulations. A structural assessment was required to design and verify these works. The project foresaw the opening of some new windows and doors in one façade wall. The cylinders tested within the present research were extracted from the same wall portions that were going to be eventually removed to make room to new openings.

The campaign with code "MC" studied a residential building located in Rambla de Catalunya, one of the main streets of Barcelona (Fig. 7b). This construction was built in 1930 in Noucentist style, and stands as a good example of bourgeois architecture of Barcelona's Eixample neighbourhood. The load bearing masonry wall structure supports floors made of steel beams with small ceramic vaults in between. The building originally hosted 6-storeys, and two additional floors were added at the top in the second half of the 20th century, as in many other constructions of this area. This modification changed the loading conditions envisaged in the original project. Recently and prior to the execution of some renovation works, a structural assessment of the masonry structure was carried out. The assessment included inspection works to characterize the masonry mechanical properties. Again, the cylinders were extracted from wall portions to be demolished as part of the on-going renovation works. 
The campaign with code "MD" involved a historical building in the district of Ciutat Vella (Fig. 7c). Built in the first half of the $19^{\text {th }}$ century in Neoclassical style, this housing complex reflects the specific economical context of the time. The building stands out by the high-quality materials used, the stone masonry elements of the facades and the overall size of the construction. Brick masonry walls constitute the load bearing structure, which supports the floors made of timber beams with ceramic vaults in between. As in the former cases, the on-going renovation works motivated and allowed the extraction of the cylinders.


Fig. 7. a) View of the building of the "Fabra i Coats" industrial complex in Barcelona studied in campaign "MB", b) main façade of the residential building at Rambla de Catalunya Street in Barcelona studied in campaign "MC", c) façade of the housing complex in the district of Ciutat Vella in Barcelona studied in campaign "MD".

During the visits to the three buildings, sets of bricks and fragments of mortar joints were extracted. Bricks had average dimensions of $291 \times 140.5 \times 52 \mathrm{~mm}^{3}$ in campaign "MB", $294 \times 145 \times$ 
$49 \mathrm{~mm}^{3}$ in campaign "MC" and $294 \times 145 \times 45 \mathrm{~mm}^{3}$ in campaign "MD". The three sets of bricks showed variability in grain size and colour. Brick pieces of $140 \times 140 \mathrm{~mm}^{2}$ and $100 \times 100 \mathrm{~mm}^{2}$ were cut respectively for campaign "MB" and campaigns "MC" and "MD". These brick pieces and mortar fragments were prepared and tested in compression following the procedures described in Section 2.1 for campaign "MA". Table 3 shows the corresponding results. The variability observed by visual inspection was also reflected in the compressive strength of bricks $\left(f_{b}\right)$, particularly in the case of campaign "MC". Bricks of campaign "MD" were twice stronger than those of campaigns "MB" and "MA", and three times stronger than the bricks of campaign "MC".

Table 3. Experimental compressive strengths of bricks $\left(f_{b}\right)$ and mortar $\left(f_{m_{-}} D P T\right)$ of campaigns "MB", "MC" and "MD".

\begin{tabular}{|c|c|c|c|c|c|c|c|c|}
\hline "MB" & $f_{b}$ & $f_{m \_D P T}$ & "MC" & $f_{b}$ & $f_{m \_D P T}$ & "MD" & $f_{b}$ & $f_{m \_D P T}$ \\
\hline Average (MPa) & 18.80 & 0.62 & Average (MPa) & 10.74 & 1.52 & Average (MPa) & 35.45 & 3.1 \\
\hline $\begin{array}{c}\text { No. of } \\
\text { specimens }\end{array}$ & 6 & 12 & $\begin{array}{c}\text { No. of } \\
\text { specimens }\end{array}$ & 12 & 28 & $\begin{array}{c}\text { No. of } \\
\text { specimens }\end{array}$ & 10 & 32 \\
\hline $\mathrm{CV}$ & $12.4 \%$ & $16.0 \%$ & $\mathrm{CV}$ & $28.0 \%$ & $35.0 \%$ & $\mathrm{CV}$ & $14.8 \%$ & $55.4 \%$ \\
\hline
\end{tabular}

The masonry walls investigated in campaign "MB" were $600 \mathrm{~mm}$ thick, built in English bond with variable mortar joint thickness between $10 \mathrm{~mm}$ and $15 \mathrm{~mm}$ (Fig. 8a). The walls investigated in campaigns "MC" and "MD" were interior single leaf walls $145 \mathrm{~mm}$ thick built in running bond (Fig. 8c and e). The mortar joint thickness varied between $14 \mathrm{~mm}$ and $17 \mathrm{~mm}$ in the former and between 10 and $15 \mathrm{~mm}$ in the latter. The quality of workmanship was better in the types of masonry "MB" ad "MD" in terms of regularity and complete filling of mortar joints.

Up to seven specimens of each cylinder type, $90 \mathrm{~mm}$ and $150 \mathrm{~mm}$, were extracted in the three campaigns (Fig. 8b, d and f). Two additional specimens of $150 \mathrm{~mm}$ were extracted in campaign "MD". The coring followed the same dry procedure mentioned in Section 2.2. It is worth to remark the advantages of this technique, as already reported in $[6,16]$. The total absence of water protected the integrity of the weak mortar joints and guaranteed the efficiency of the full process. Only two operators could easily handle the equipment and a half working day was enough to extract the required amount 
of cores. The extraction of $90 \mathrm{~mm}$ cylinders was easier than for the $150 \mathrm{~mm}$ cores. Once the coredrilling machine was fixed to the masonry wall, the coring bit could be moved and the samples extracted along a circumferential path. Within a wall, finding an adequate spot to extract a $90 \mathrm{~mm}$ sample resulted easier than for a $150 \mathrm{~mm}$ core. Additionally, the specimens of campaign "MB", which were extracted from $600 \mathrm{~mm}$ thick walls, were sawn to adjust their depth to the width of the constituent bricks $(\approx 145 \mathrm{~mm})$. 

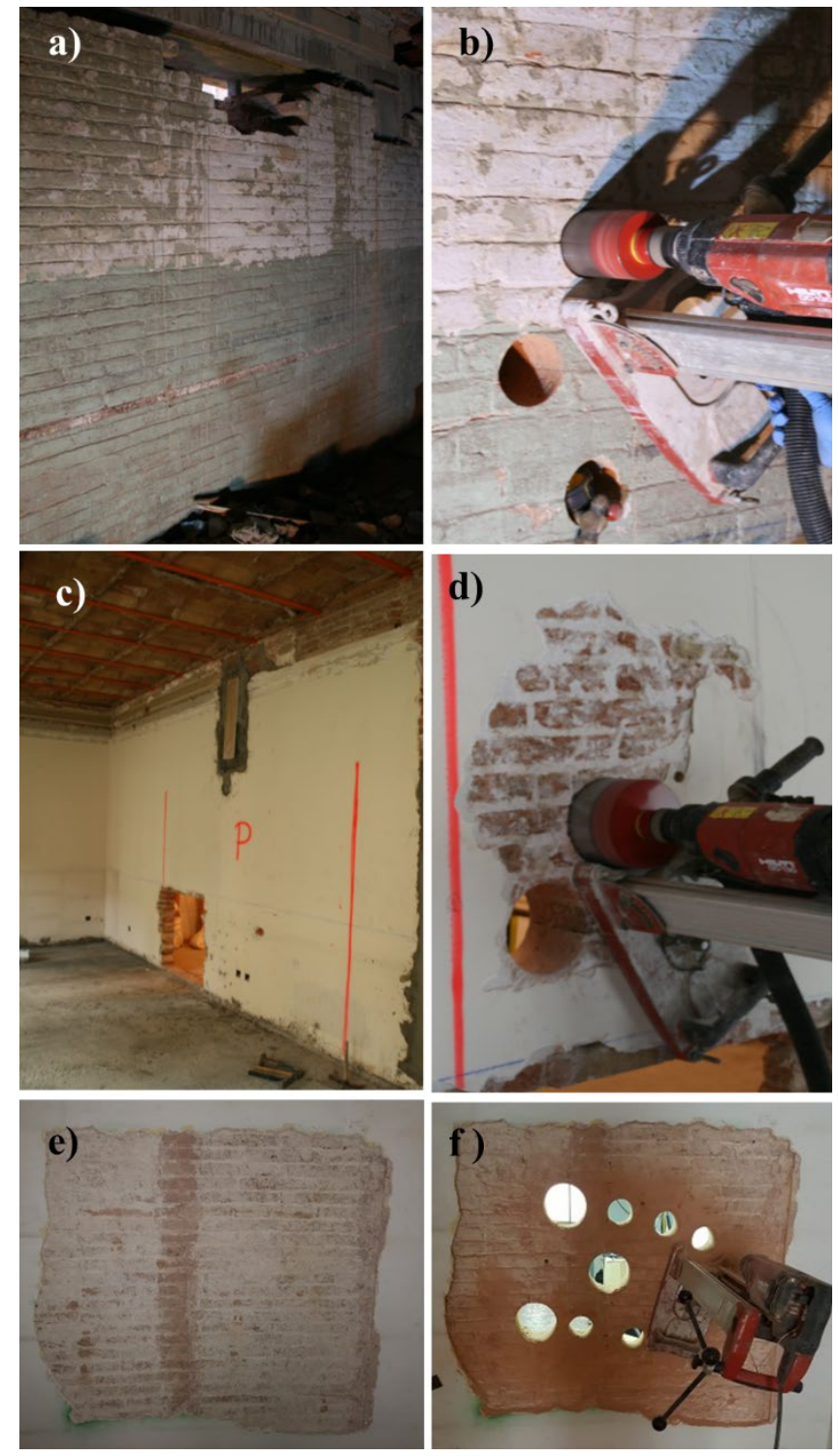

Fig. 8. a) Façade wall investigated in "Fabra i Coats" factory and b) in-situ core drilling for campaign "MB", c) inner wall of the analysed building in Rambla Catalunya street and d) in-situ core drilling for campaign "MC", e) inner wall of the building in Ciutat Vella and f) in-situ core drilling for campaign "MD".

The extracted specimens of the three campaigns were regularized with mortar caps and tested in compression, as described in Sections 2.2 and 2.3 for campaign "MA". Fig. 9, Fig. 10 and Fig. 11 show the stress-strain curves of the tests for the three campaigns. The trends are similar to those discussed in Section 2 for the campaign "MA". The cracking sequences, which are illustrated by the failure examples shown in Fig. 12, resulted very similarly to those of campaign "MA". 

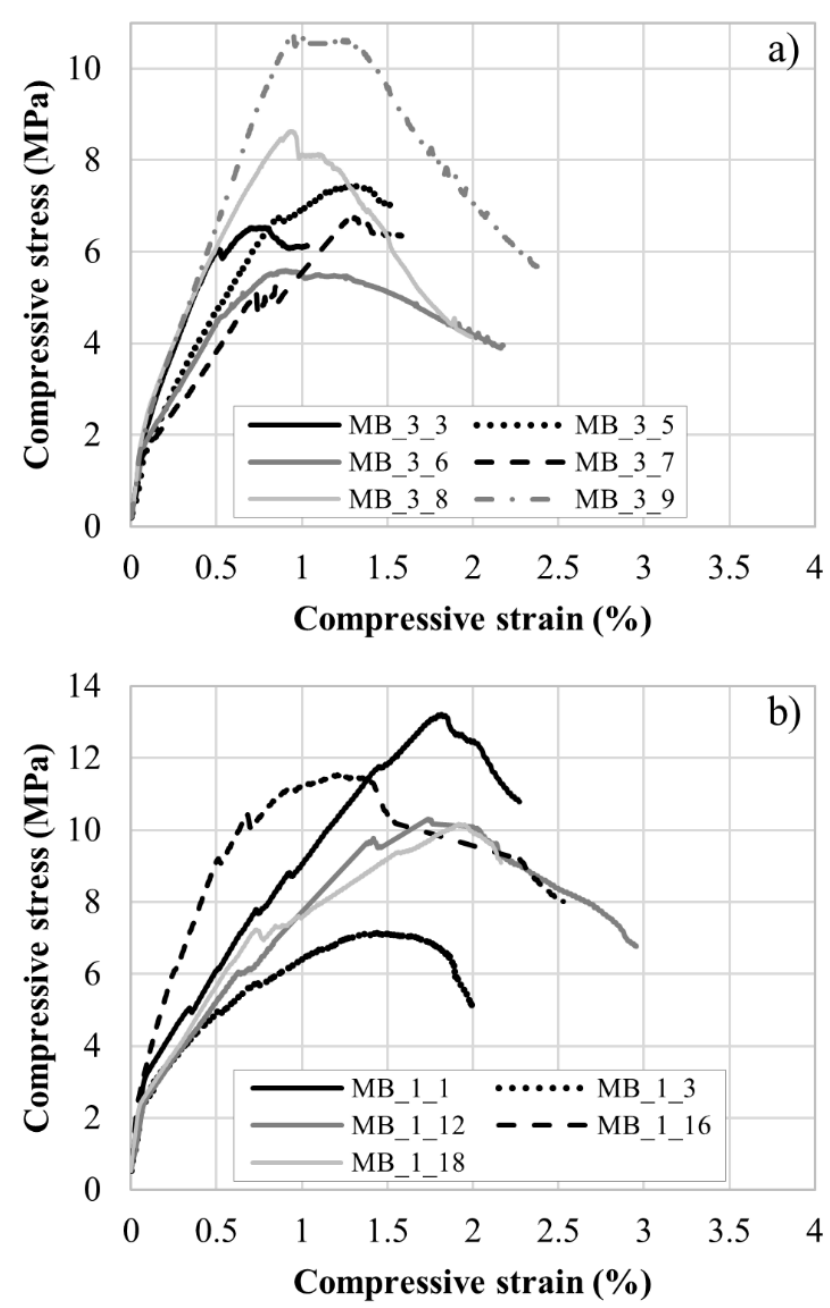

Fig. 9. Compressive stress-strain curves of campaign "MB": a) $150 \mathrm{~mm}$ samples and b) $90 \mathrm{~mm}$ samples. 



Fig. 10. Compressive stress-strain curves of campaign "MC": a) $150 \mathrm{~mm}$ samples and b) $90 \mathrm{~mm}$ samples. 



Fig. 11. Compressive stress-strain curves of campaign "MD": a) $150 \mathrm{~mm}$ samples and b) $90 \mathrm{~mm}$ samples. 



Fig. 12. Modes of failure in the $150 \mathrm{~mm}$ (left) and $90 \mathrm{~mm}$ (right) core samples extracted from existing masonry buildings: a) and b) campaign “MB”, c) and d) campaign "MC”, e) and f) campaign "MD”.

Table 4, Table 5 and Table 6 present the compressive strength and Young's modulus results obtained from both types of cylindrical specimen for the campaigns "MB", "MC" and "MD" respectively. The discussion of the results is included in Section 4.1. 
Table 4. Compressive strengths $\left(f_{c}\right)$ and Young's moduli $(E)$ of $150 \mathrm{~mm}$ and $90 \mathrm{~mm}$ masonry cylinders of campaign "MB".

\begin{tabular}{cccccc}
\hline \multicolumn{2}{c}{ "MB" 150 mm cylinders } & \multicolumn{3}{c}{ "MB" 90 mm cylinders } \\
\hline ID & $\begin{array}{c}f_{c, 150 \mathrm{~mm}} \\
(\mathrm{MPa})\end{array}$ & $\begin{array}{c}E_{150 \mathrm{~mm}} \\
(\mathrm{MPa})\end{array}$ & ID & $\begin{array}{c}f_{c, 90 \mathrm{~mm}} \\
(\mathrm{MPa})\end{array}$ & $\begin{array}{c}E_{90 \mathrm{~mm}} \\
(\mathrm{MPa})\end{array}$ \\
\hline MB_3_0 & 9.13 & -- & MB_1_0 & 8.26 & -- \\
MB_3_3 & 6.53 & 2580 & MB_1_1 & 13.22 & 3027 \\
MB_3_5 & 7.45 & 1663 & MB_1_3 & 7.14 & 2551 \\
MB_3_6 & 5.60 & 2019 & MB_1_6 & 8.51 & -- \\
MB_3_7 & 6.75 & 1992 & MB_1_12 & 10.31 & 2430 \\
MB_3_8 & 8.64 & 2902 & MB_1_16 & 11.55 & 3727 \\
MB_3_9 & 10.74 & 2665 & MB_1_18 & 10.17 & 3719 \\
\hline Average & 7.83 & 2304 & Average & 9.88 & 3091 \\
CV & $22.6 \%$ & $20.9 \%$ & CV & $21.2 \%$ & $20.0 \%$ \\
\hline
\end{tabular}

Table 5. Compressive strengths $\left(f_{c}\right)$ and Young's moduli $(E)$ of $150 \mathrm{~mm}$ and $90 \mathrm{~mm}$ masonry cylinders of campaign "MC".

\begin{tabular}{cccccc}
\hline \multicolumn{2}{c}{ "MC" $\mathbf{1 5 0} \mathbf{~ m m}$ cylinders } & \multicolumn{3}{c}{ "MC" $90 \mathbf{~ m m}$ cylinders } \\
\hline ID & $\begin{array}{c}f_{c, 150 \mathrm{~mm}} \\
(\mathrm{MPa})\end{array}$ & $\begin{array}{c}E_{150 \mathrm{~mm}} \\
(\mathrm{MPa})\end{array}$ & ID & $\begin{array}{c}f_{c, 90 \mathrm{~mm}} \\
(\mathrm{MPa})\end{array}$ & $\begin{array}{c}E_{90 \mathrm{~mm}} \\
(\mathrm{MPa})\end{array}$ \\
\hline MC_3_1 & 6.76 & 1416 & MC_1_1 & 7.06 & 1797 \\
MC_3_2 & 4.94 & 1830 & MC_1_2 & 7.81 & 1490 \\
MC_3_3 & 5.44 & 1827 & MC_1_3 & 7.44 & 1290 \\
MC_3_4 & 5.20 & 1291 & MC_1_4 & 6.82 & 1840 \\
MC_3_5 & 5.47 & -- & MC_1_5 & 7.01 & 1956 \\
MC_3_6 & 5.61 & 1688 & MC_1_6 & 6.84 & 1906 \\
MC_3_7 & 3.55 & 1360 & MC_1_7 & 7.18 & 1495 \\
\hline Average & 5.28 & 1569 & Average & 7.16 & 1682 \\
CV & $18.1 \%$ & $15.4 \%$ & CV & $4.9 \%$ & $15.1 \%$ \\
\hline
\end{tabular}

Table 6. Compressive strengths $\left(f_{c}\right)$ and Young's moduli $(E)$ of $150 \mathrm{~mm}$ and $90 \mathrm{~mm}$ masonry cylinders of campaign "MD".

\begin{tabular}{cccccc}
\hline \multicolumn{2}{c}{ "MD" 150 mm cylinders } & \multicolumn{3}{c}{ "MD" 90 mm cylinders } \\
\hline ID & $\begin{array}{c}f_{c, 150 \mathrm{~mm}} \\
(\mathrm{MPa})\end{array}$ & $\begin{array}{c}E_{150 \mathrm{~mm}} \\
(\mathrm{MPa})\end{array}$ & ID & $\begin{array}{c}f_{c, 90 \mathrm{~mm}} \\
(\mathrm{MPa})\end{array}$ & $\begin{array}{c}E_{90 \mathrm{~mm}} \\
(\mathrm{MPa})\end{array}$ \\
\hline MD_3_1 & 11.91 & 4258 & MD_1_1 & 16.67 & 5265 \\
MD_3_2 & 7.68 & 3362 & MD_1_2 & 10.36 & 3157 \\
MD_3_3 & 8.14 & 1783 & MD_1_3 & 10.04 & 2958 \\
MD_3_4 & 9.73 & 3927 & MD_1_4 & 13.72 & 3598 \\
MD_3_5 & 11.18 & 2948 & MD_1_5 & 11.66 & 3278 \\
MD_3_6 & 7.80 & 4157 & MD_1_6 & 14.86 & 3590 \\
MD_3_7 & 8.05 & 3951 & MD_1_7 & 12.02 & 4498 \\
MD_3_8 & 13.26 & 3614 & & & \\
MD_3_9 & 6.75 & 3035 & & & \\
\hline Average & 9.39 & 3448 & Average & 12.76 & 3763 \\
CV & $23.9 \%$ & $22.6 \%$ & CV & $19.1 \%$ & $22.0 \%$ \\
\hline
\end{tabular}




\section{Discussion}

\subsection{Comparison among the four experimental campaigns}

The experimental programme described in Section 2 consisted in testing samples extracted from masonry walls built in the laboratory. Useful remarks were drawn from the comparison between the results of the more novel MDT technique consisting in tests on $90 \mathrm{~mm}$ masonry cylinders with one mortar joint and the results of the relatively well-studied technique involving tests on $150 \mathrm{~mm}$ cylinders with two horizontal and one vertical mortar joints. Section 3 described three additional campaigns on samples extracted from real historical buildings that aimed to confirm the aforementioned findings for the case of real existing masonry.

The comparison of the stress-strain curves depicted in Fig. 4, Fig. 9, Fig. 10 and Fig. 11 shows similar recognizable trends for the two types of specimen studied. The first branch observed in all the curves up to low values of stress is related to the specific testing protocol adopted in this research, which included the performance of initial loading/unloading cycles. Then, the curves can be generally divided into three sections: a linear branch, a non-linear behaviour before the peak stress and a softening response after the peak stress. Some differences are observed, however, in the stress-strain curves. Longer linear branches are generally observed in the case of the $150 \mathrm{~mm}$ specimens that, in some cases, develop up to almost the peak stress. For the $90 \mathrm{~mm}$ samples, usually higher values of the strain at peak stress are detected. These observations apply for the four types of masonry investigated.

The examples of tested specimens shown in Fig. 12 for campaigns "MB", "MC" and "MD" confirm the failure mechanisms reported for the masonry of campaign "MA". The 56 cylinders tested in the context of this research failed in a very similar way. The failures were characterized by pseudovertical cracks appearing firstly on the bricks that caused eventually the detachment of the external parts, leaving a final sandglass shaped core. These features are in agreement with the findings described by former researches on $150 \mathrm{~mm}$ cores [2-6] and $100 \mathrm{~mm}$ cores [9]. 
The failure is consistent with the common understanding of the mechanical behaviour of masonry in compression [24,25]. Because of the different elastic properties of the two constituents, i.e. stiff bricks and soft mortar in the types of masonry studied in this research, different stress states develop within the sample. Due to the mortar's trend to experience a much higher lateral expansion than the bricks, the units experience horizontal tensile stresses causing vertical splitting cracks in them. The sandglass shape results from the confinement exerted by the caps, which is more pronounced in the top and bottom sections of the cylinders than in the mid-section.

Additional evidence that supports the use of core samples to characterize masonry may be found in the possible parallelism between the tests investigated herein and the tests on standard prismatic specimens for masonry [26]. EN 1052-1 [27] proposes the use of small walls to estimate the compressive strength of new masonry. These specimens include both bed and head joints and might be compared to the $150 \mathrm{~mm}$ cylinders, which also include a head joint. Conversely, ASTM C1314 [28] recommends the use of simpler stack bond prisms, without head joints, like the $90 \mathrm{~mm}$ cylinder investigated herein.

The results on the compressive strength and the Young's modulus reported in Table 2, Table 4, Table 5 and Table 6 for the four experimental campaigns are summarized in Fig. 13 and Fig. 14. As in campaign "MA", the rest of campaigns confirm that tests on the $90 \mathrm{~mm}$ samples provide higher values of the compressive strength (Fig. 13). This was explained in Section 2 as due to the size effect related to the different geometries. The presence of more mortar joints in the $150 \mathrm{~mm}$ samples may be especially relevant as they introduce more weak points. Additionally, vertical stresses may be better distributed in the $90 \mathrm{~mm}$ cylinders thanks to the absence of head joints. However, the ratio of the strengths obtained for the two types of specimen, calculated as $R_{c}=f_{c, 150 \mathrm{~mm}} / f_{c, 90 \mathrm{~mm}}$, is very similar for the four campaigns. The ratios obtained are $0.75,0.79,0.74$ and 0.74 for campaigns "MA", "MB", "MC" and "MD" respectively. 
The coefficients of variation found for the compressive strength in the campaigns on real buildings are still moderate, and they can be fully explained by the variability of the materials. In campaigns "MB" and "MD", the scattering for the two types of cylinder is very similar. This confirms that testing smaller cylinders does not introduce further variability into the results. Furthermore, a remarkably low value of the coefficient of variation, below 5\%, was obtained in the case of $90 \mathrm{~mm}$ samples of campaign "MC".

With regard to the determination of the Young's modulus, the values obtained with $90 \mathrm{~mm}$ specimens are higher than the results derived from $150 \mathrm{~mm}$ samples in the four experimental campaigns (Fig. 14). This outcome was explained in Section 2 as due to the presence of one additional horizontal mortar joint in the $150 \mathrm{~mm}$ cores. The higher values of Young's modulus and strain at peak stress in $90 \mathrm{~mm}$ cores are not contradictory, since the latter can be explained by the higher strengths reached by $90 \mathrm{~mm}$ specimens. The ratio of Young's moduli $\left(R_{E}=E_{150 \mathrm{~mm}} / E_{90 \mathrm{~mm}}\right)$ between the two types of specimen presented a certain scatter. The values ranged from 0.79 and 0.75 for campaigns "MA" and "MB" to 0.93 and 0.92 for campaigns "MC" and "MD".

The scattering observed in the estimation of the Young's modulus is also moderate and similar to that observed for the compressive strength. The variability is consistent between the two types of cylinder in the three campaigns on real buildings. As occurred in campaign "MA", no additional scattering may be attributable to the use of smaller cylinders. It is also significant that both types of specimen provide similar values of the ratio relating the Young's modulus to the compressive strength $\left(E / f_{c}\right)$ for each type of masonry investigated. These ratios range approximately from 200 to 350 in all the cases. These values are realistic for historical lime mortar brickwork $[29,30]$. 


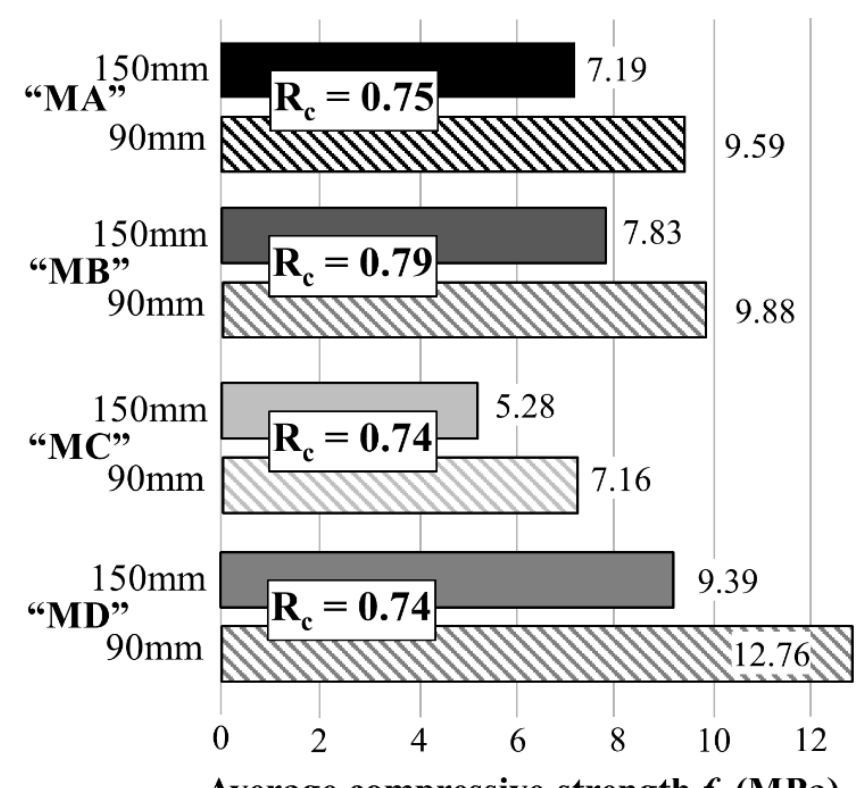

Average compressive strength $f_{c}$ (MPa)

Fig. 13. Comparison of compressive strengths $\left(f_{c}\right)$ results obtained for $150 \mathrm{~mm}$ and $90 \mathrm{~mm}$ cylinders for the four types of masonry investigated.

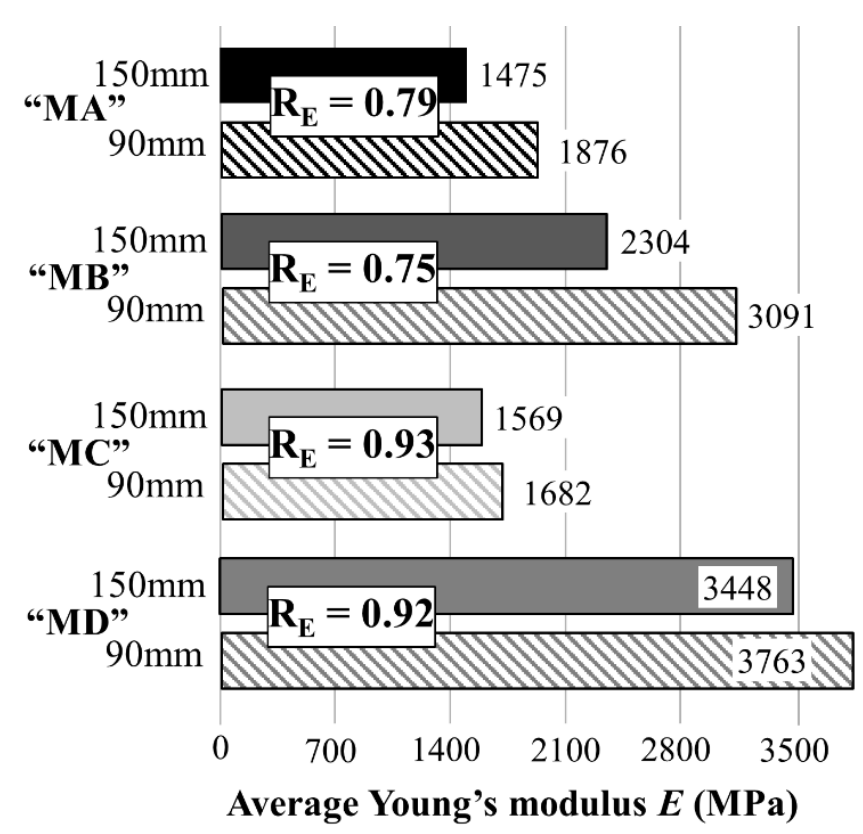

Fig. 14. Comparison of Young's moduli $(E)$ results obtained for $150 \mathrm{~mm}$ and $90 \mathrm{~mm}$ cylinders for the four types of masonry investigated.

Fig. 13 and Fig. 14 allow also analysing the consistency of the results in terms of the relative values obtained for each type of masonry. The highest values of the compressive strength (Fig. 13) 
correspond to the masonry of Ciutat Vella building (campaign "MD") that was constituted with the strongest materials (Table 3). The masonry of Fabra i Coats factory (campaign "MB") is the second strongest. The weakness of its mortar (Table 3) is compensated with the combination of strong bricks and reduced thickness of the joints. Slightly lower values were obtained for the masonry built in the laboratory (campaign "MA"). The lowest masonry strength was found in the building in Rambla de Catalunya Street (campaign "MC"). This may be related to the weaker bricks used for its construction (Table 3). Both types of cylinder are able to predict the same trends.

The Young's modulus of the masonry of campaign "MD" is consistently characterized as the highest one by the two types of specimen. These highest values of Young's moduli may be due to the combination of thin joints and strong mortar that characterizes this masonry. The thinness of the mortar joints as well as the thickness of the bricks also explain the high values of Young's moduli obtained in campaign "MB". A simple 1-D homogenization model [6,31] to estimate the Young's modulus can justify the former conclusions. Conversely, similar values of Young's moduli have been obtained for the other two types of masonry, whose constituents have thicknesses that are more similar.

With the exception of the compressive strength of campaign "MC" obtained by $90 \mathrm{~mm}$ specimens, which presented a remarkably low variability, the scattering found in the determination of both compressive strength and Young's modulus presents also an expected trend. Campaigns "MB", "MC" and "MD" present more variable results than campaign "MA". This is related to the higher variability of historical masonry, which is intrinsic to its traditional constructive techniques and materials, in addition to a possible decay (not evident in the materials analysed) and the possible influence of the experienced load histories. This variability contrasts with the more controlled processes used to build the walls in the laboratory. 


\subsection{Size effect on the compressive strength and Young's modulus of cylindrical specimens}

As presented in the Section 4.1, the $90 \mathrm{~mm}$ specimens provide higher values of both the compressive strength and the Young's modulus than the $150 \mathrm{~mm}$ ones. Fig. 15 shows graphically the size effect relationships on both properties. They are calculated as the linear regressions of the ratios $R_{c}$ and $R_{E}$ between the $150 \mathrm{~mm}$ and $90 \mathrm{~mm}$ core samples for the four experimental campaigns considered in this research.

The constant of proportionality is 0.75 for the four pairs of compressive strength values derived from the $150 \mathrm{~mm}$ cylinders $\left(f_{c, 150 \mathrm{~mm}}\right)$ and the $90 \mathrm{~mm}$ cores $\left(f_{c, 90 \mathrm{~mm}}\right)$. The approach followed in this research, which combines experimental results from laboratory controlled materials and real historical members spanning different levels of strength, allows obtaining a regression with a satisfactory coefficient of determination $r^{2}$ equal to 0.975 . The increase of the compressive strength with the reduction of the specimen's size is consistent with the trends obtained in previous experimental and analytical studies on prismatic masonry samples $[11,32,33]$.

Based on the aforementioned results, the size-effect relationship on compressive strength of masonry cylindrical specimens can be written as follows (Eq. 1):

$$
f_{c, 150 \mathrm{~mm}} \cong 0.75 f_{c, 90 \mathrm{~mm}}
$$

The constant of proportionality is 0.85 for the four pairs of Young's modulus values derived from the $150 \mathrm{~mm}$ cylinders $\left(E_{150}\right)$ and the $90 \mathrm{~mm}$ cores $\left(E_{90}\right)$. Although the ratios $R_{E}$ present a larger scattering than those of the compressive strengths $R_{c}$, the obtained coefficient of determination $r^{2}$ is still higher than 0.9 and equal to 0.92 . 
a)
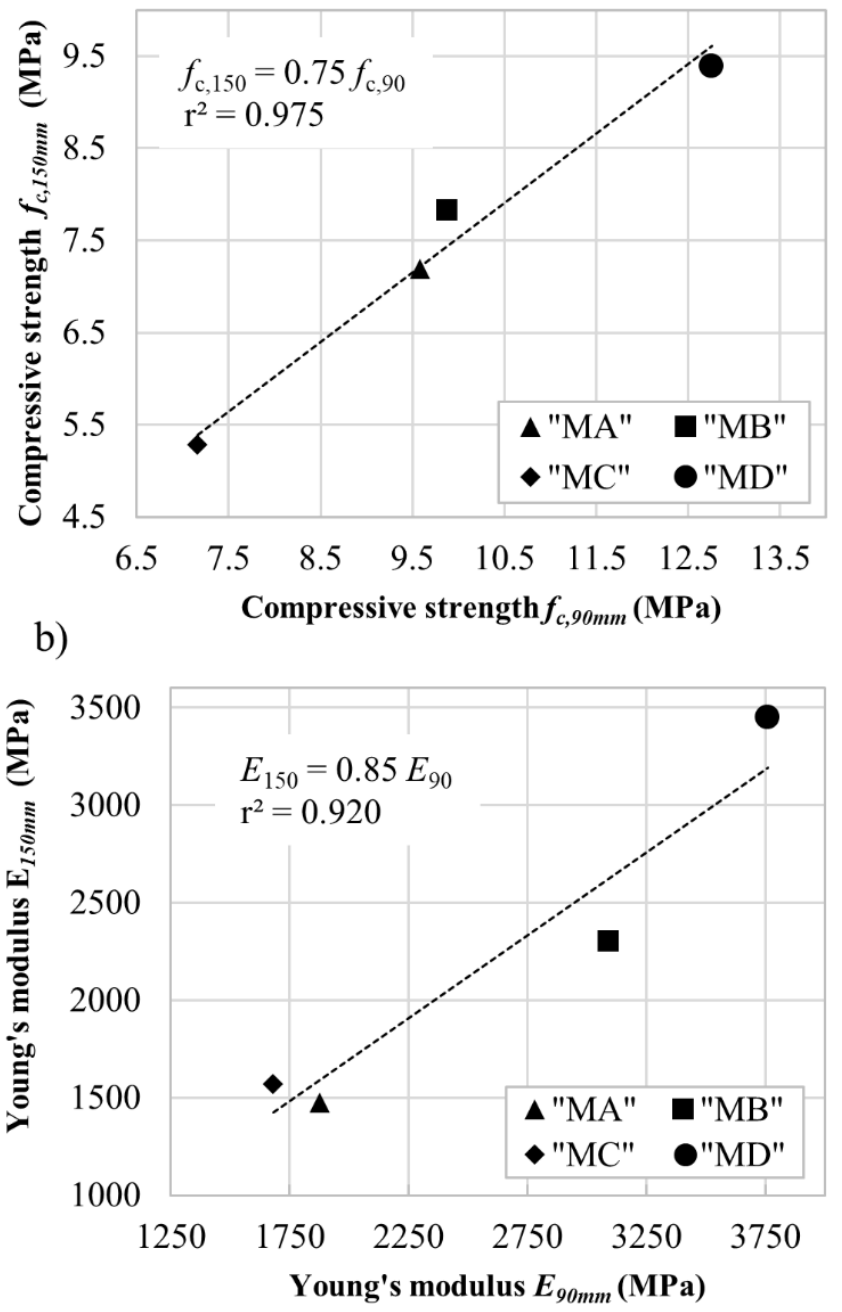

Fig. 15. Size effect on a) compressive strength and b) Young's modulus obtained from $150 \mathrm{~mm}$ and $90 \mathrm{~mm}$ cylinders for the four types of masonry investigated in this research.

\subsection{Estimation of the compressive strength of masonry and comparison with available predictive expressions}

As stated in Section 1, the $150 \mathrm{~mm}$ specimens have been shown suitable for a direct evaluation of the masonry compressive strength by previous researches [5,7,23]. Eq. 2 expresses this approximate evaluation as:

$f_{c}^{*} \cong f_{c, 150 \mathrm{~mm}}$ 
where $f_{c}^{*}$ is the compressive strength of the masonry being inspected. Other references $[2,4]$ include in the former relationship a correction factor because they consider the diametrical section to calculate the acting stresses and the load is applied differently as described in Section 2.2. Taking into account this latter remark, all the aforementioned references $[2,4,5,7,23]$ propose equivalent expressions.

Combining the former Equations 1 and 2, a new practical approach can be proposed consisting in the extraction and testing of $90 \mathrm{~mm}$ specimens and the estimation of the compressive strength of masonry through the application of the following expression (Eq. 3):

$$
f_{c}^{*} \cong 0.75 f_{c, 90 \mathrm{~mm}}
$$

Table 7 presents the application of Equation 3 to the four types of masonry investigated herein. The estimations of the compressive strength are compared to the predictions provided by the application of other approaches. Among the available possibilities, one consists in testing the individual components, i.e. bricks and mortar, and applying empirical or analytical correlations to estimate the mechanical properties of the composite material from those of the components $[30,34,35]$. This approach faces several difficulties. One of them stems from the applicability of the equations available in literature. The expressions with an empirical basis, like those proposed by some available standards for the design of new masonry structures, are in principle only adequate for the new construction materials for which they were calibrated and show limitations in the applicability to historical masonry. Another major difficulty lays in the characterization of the existing mortar $[17,36]$, which is hindered by the impossibility of extracting non-disturbed or normalized prismatic samples [37]. A possible solution to this difficulty is found in extracting joint fragments and testing them under double punch compression, as it is done in the present research and explained in Section 2.1.

Table 7 includes the comparison between the experimental estimation of the compressive strength by Equation 3 and the predictions of two expressions available in building codes $[38,39]$. The term $f_{c, A C I}$ represents the compressive strength estimated by the unit strength method expression 
proposed in the Commentary on the Specification for Masonry Structures ACI 530.1-02 [38]. This empirical expression correlates the strength of the masonry with the strength of the units. The term $f_{c, E C 6}$ indicates the value obtained with the expression proposed by Eurocode 6 [39]. In the latter, the characteristic compressive strength of the composite material is correlated with the average compressive strengths of both mortar and units. The values reported in Table 7 have been previously converted into mean value by multiplying by a factor equal to 1.2 as recommended in EN1052-1 [27]. The mortar strength introduced into the equation is the one obtained via the double punch tests. The columns on the right of the predictions express the difference in percentage terms $(\Delta \%)$ with respect to the experimental estimation.

Table 7. Experimental estimation of masonry compressive strength $\left(f_{c}^{*}\right)$ vs. predictions from expressions of ACI [38] $\left(f_{c, A C I}\right)$ and EC6 [39] $\left(f_{c, E C 6}\right) . \Delta \%$ expresses the difference in percentage of the predictions with respect to the experimental estimation.

\begin{tabular}{cccccc}
\hline Masonry & $f_{c} *(\mathrm{MPa})$ & $f_{c, A C I}(\mathrm{MPa})$ & $\Delta \%$ & $f_{c, E C \sigma}(\mathrm{MPa})$ & $\Delta \%$ \\
\hline "MA" - Lab & 7.19 & 6.24 & $-13.2 \%$ & 5.63 & $-21.7 \%$ \\
"MB" - Fabra & 7.41 & 6.52 & $-12.0 \%$ & 4.46 & $-39.8 \%$ \\
"MC" - Rambla & 5.37 & 4.90 & $-8.8 \%$ & 3.94 & $-26.6 \%$ \\
"MD" C. Vella & 9.57 & 9.84 & $2.8 \%$ & 11.26 & $17.7 \%$ \\
\hline
\end{tabular}

The expression proposed by the ACI Specification [38] provides similar values to the experimental estimations, with a close agreement of $2.8 \%$ in the case of the masonry made with the strongest bricks (campaign "MD”). In the latter, the equation of the Eurocode 6 [39] provides a nonconservative estimation, while it yields more conservative estimations in the cases of campaigns "MA", "MB" and "MC". It is remarkable that the highest difference is found for campaign "MB", which is the type of masonry with the poorest mortar.

In the cases of low strength materials (campaigns "MA", "MB" and "MC"), the expressions proposed by the building standards have provided more conservative values of the compressive strength compared with the experimental results. Under the assumption that the values obtained by means of the use of masonry cylinders are closer to the actual compressive strength of masonry, the 
investigated technique can be regarded as a convenient tool for mechanical characterization. Since an accurate estimation of the mechanical properties helps to reduce uncertainties during the structural assessment, the design of possible interventions, such as retrofit or strengthening, can be less prominent and thus more respectful of the cultural value of existing heritage buildings.

\section{Conclusions}

This paper has presented an experimental research on the characterization of the compressive mechanical properties of existing masonry. The laboratory testing of core samples extracted from masonry walls has been investigated as a MDT inspection technique. Two types of core, the already studied and validated three-joint cylinder with diameter of $150 \mathrm{~mm}$ and the proposed one-joint cylinder with diameter of $90 \mathrm{~mm}$, have been tested and compared to study the effect associated to the reduction of size. The aim in reducing the cylinder's size is to limit the damage caused to the structure during the sampling and allowing a more efficient extraction and testing. Tests on the two types of cylinder were investigated on masonry walls built in the laboratory with historical-like materials and then applied to three real case studies of historical buildings in Barcelona.

The following conclusions can be drawn from the analysis of the results:

- The dry procedure applied to drill the cores has proved to be a clean and efficient method for the extraction of cylindrical specimens in existing buildings. The extraction of $90 \mathrm{~mm}$ cylinders was comparatively easier than the extraction of $150 \mathrm{~mm}$ cylinders.

- The experimental evidence confirms the adequacy of the $90 \mathrm{~mm}$ samples to reproduce the expected mechanical behaviour of masonry in compression. Similar failure mechanisms were found for the two cylinder types. It has been observed that tests on both cylinder types adequately represent the complex interaction between bricks and mortar that characterizes the masonry response in compression. 
- The size of the core sample has been found to have significant effect on the compressive strength and the Young's modulus. The comparison of the four experimental campaigns has shown that the tests on the two types of specimen provide consistent results and the same logical trends for the compressive strength and the Young's modulus of masonry. The moderate scattering obtained in the tests can be fully explained by the variability found in the constituents' material properties.

- The comparison of the compressive strength results obtained from $150 \mathrm{~mm}$ and $90 \mathrm{~mm}$ specimens has provided an almost uniform relation for the four different experimental campaigns. A linear regression of the results has yielded a proportionality constant of 0.75 . This coefficient may be considered applicable to masonry types similar to the ones investigated, i.e. made of solid clay bricks -with normalized compressive strengths from 10 to $35 \mathrm{MPa}$ - and joints made of lime mortar -with compressive strengths from 0.60 to $3 \mathrm{MPa}$.

- Testing small $90 \mathrm{~mm}$ diameter cores has proved to be an advantageous and promising technique for the evaluation of the resisting properties of masonry in compression. A suggested set of 6 specimens extracted from an existing structural member may provide a reliable estimation of the compressive strength and an acceptable estimation of the Young's modulus.

\section{Acknowledgements}

The authors gratefully acknowledge the financial support from the Ministry of Economy and Competitiveness and from the Ministry of Science, Innovation and Universities of the Spanish Government, as well as that of the ERDF (European Regional Development Fund) through projects MULTIMAS (Multiscale techniques for the experimental and numerical analysis of the reliability of masonry structures, ref. num. BIA2015-63882-P) and SEVERUS (Multilevel evaluation of seismic vulnerability and risk mitigation of masonry buildings in resilient historical urban centres, ref. num. RTI2018-099589-B-I00). Support from Secretaria d'Universitats i Investigació de la Generalitat de 
Catalunya through a predoctoral grant awarded to the first author is also gratefully acknowledged. The authors would like to thank Larisa García-Ramonda for her helpful contributions.

\section{References}

[1] UIC, Leaflet 778-3R: Recommendations for the inspection, assessment and maintenance of masonry arch bridges, 1995.

[2] A. Brencich, E. Sterpi, Compressive Strength of Solid Clay Brick Masonry: Calibration of Experimental Tests and Theoretical Issues, in: P. B. Lourenço, C. Modena, P. Roca, S. Agrawal (Eds.), SAHC 2006 - Struct. Anal. Hist. Constr., Macmillan India Let., 2006: pp. 757-766.

[3] A. Brencich, D. Sabia, Experimental identification of a multi-span masonry bridge: The Tanaro Bridge, Constr. Build. Mater. 22 (2008) 2087-2099. doi:10.1016/j.conbuildmat.2007.07.031.

[4] P. Matysek, Compressive strength of brick masonry in existing buildings — research on samples cut from the structures, in: C. Modena, F. da Porto, M.R. Valluzzi (Eds.), Brick Block Mason. - Trends, Innov. Challenges, Taylor \& Francis Group, 2016: pp. 1741-1747.

[5] L. Pelà, P. Roca, A. Benedetti, Mechanical Characterization of Historical Masonry by Core Drilling and Testing of Cylindrical Samples, Int. J. Archit. Herit. (2016) 150817093153002. doi:10.1080/15583058.2015.1077906.

[6] L. Pelà, E. Canella, A. Aprile, P. Roca, Compression test of masonry core samples extracted from existing brickwork, Constr. Build. Mater. 119 (2016) 230-240. doi:10.1016/j.conbuildmat.2016.05.057.

[7] L. Pelà, E. Canella, K. Kasioumi, P. Roca, D. Marastoni, Complete experimental characterization of lime mortar and clay brick masonry, in: C. Modena, F. da Porto, M.R. Valluzzi (Eds.), Brick Block Mason. - Trends, Innov. Challenges, Taylor \& Francis Group, 2016: pp. 1799-1806.

[8] E. Sassoni, C. Mazzotti, G. Pagliai, Comparison between experimental methods for evaluating the compressive strength of existing masonry buildings, Constr. Build. Mater. $68 \quad$ (2014) 206-219. doi:10.1016/j.conbuildmat.2014.06.070.

[9] P. Matysek, T. Stryszewska, S. Kanka, Experimental research of masonry compressive strength in the Auschwitz II - Birkenau former death camp buildings, Eng. Fail. Anal. $68 \quad(2016)$ 263-274. doi:10.1016/j.engfailanal.2016.06.007. 
[10] A. Carpinteri, B. Chiaia, P. Bocca, Size dependence of strength and fracture properties of brick masonry walls, J. Eng. Mech. 123 (1997) 816-822.

[11] P.B. Lourenço, Two aspects related to the analysis of masonry structures: size effect and parameter sensitivity. Report n 03.21.1.31.25, 1997.

[12] European Committee for Standardization (CEN), EN 772-1:2011, Methods of Test for Masonry Units - Part 1: Determination of Compressive Strength, (2011).

[13] European Committee for Standardization (CEN), EN 459-1 Building lime - Part 1: Definitions, specifications and conformity criteria, (2010).

[14] Deutsches Institut für Normung (DIN), DIN 18555-9: Testing of mortar containing mineral binders - Part 9: Determining the compressive strength of hardened mortar, (1999).

[15] D. Marastoni, L. Pelà, A. Benedetti, P. Roca, Combining Brazilian Tests on masonry cores and Double Punch Tests for the mechanical characterization of historical mortars, Constr. Build. Mater. 112 (2016) 112-127. doi:10.1016/j.conbuildmat.2016.02.168.

[16] L. Pelà, K. Kasioumi, P. Roca, Experimental evaluation of the shear strength of aerial lime mortar brickwork by standard tests on triplets and non-standard tests on core samples, Eng. Struct. 136 (2017) 441-453. doi:10.1016/j.engstruct.2017.01.028.

[17] L. Pelà, P. Roca, A. Aprile, Combined In-Situ and Laboratory Minor Destructive Testing of Historical Mortars, Int. J. Archit. Herit. 12 (2018) 334-349. doi:10.1080/15583058.2017.1323247.

[18] European Committee for Standardization (CEN), EN 14580 Natural stone test methods. Determination of static elastic modulus, (2006).

[19] American Society for Testing and Materials, ASTM E111 Standard Test Method for Young's Modulus, Tangent Modulus, and Chord Modulus 1, (2010).

[20] European Committee for Standardization (CEN), EN 12390-13 Testing hardened concrete - Part 13: Determination of secant modulus of elasticity in compression, (2013).

[21] American Society for Testing and Materials, ASTM C 469-02 Standard Test Method for Static Modulus of Elasticity and Poisson's Ratio of Concrete in Compression, (2002). 
[22] A. Drougkas, P. Roca, C. Molins, Compressive strength and elasticity of pure lime mortar masonry, Mater. Struct. Constr. 49(3) (2016) 983-999. doi:DOI: 10.1617/s11527-015-0553-2.

[23] S. Jafari, R. Esposito, J. Rots, Literature review on the assessment of masonry properties by tests on core samples, in: W.J. Quist, S.J.C. Granneman, R.P.J. van Hees (Ed.), 4th WTA Int. PhD Symp., Vlaanderen, 2017: p. 172-180.

[24] A.W. Hendry, Structural Masonry, Macmillan Press Ltd, 1998.

[25] M. Como, Statics of Historic Masonry Constructions, Springer, 2013.

[26] J. Segura, L. Pelà, P. Roca, Monotonic and cyclic testing of clay brick and lime mortar masonry in compression, Constr. Build. Mater. 193 (2018) 453-466. doi:10.1016/j.conbuildmat.2018.10.198.

[27] European Committee for Standardization (CEN), EN 1052-1 Methods of test for masonry - Part 1: Determination of compressive strength, (1999).

[28] American Society for Testing and Materials, ASTM C1314-09 Standard Test Method for Compressive Strength of Masonry Prisms, (2009).

[29] M. Tomazevic, Earthquake-resistant design of masonry buildings, Imperial College Press, 1999. doi:https://doi.org/10.1142/p055.

[30] A. Drougkas, C. Molins, P. Roca, Numerical prediction of the behavior, strength and elasticity of masonry in compression, Eng. Struct. 90 (2015) 15-28. doi:10.1016/j.engstruct.2015.02.011.

[31] G.N. Pande, J.X. Liang, J. Middleton, Equivalent elastic moduli for brick masonry, Comput. Geotech. 8 (1989) 243-265. doi:10.1016/0266-352X(89)90045-1.

[32] A. Mohammed, T.G. Hughes, A. Mustapha, The effect of scale on the structural behaviour of masonry under compression, Constr. Build. Mater. 25 (2011) 303-307. doi:10.1016/j.conbuildmat.2010.06.025.

[33] C.L. Knox, D. Dizhur, J.M. Ingham, Experimental study on scale effects in clay brick masonry prisms and wall panels investigating compression and shear related properties, Constr. Build. Mater. 163 (2018) 706-713. doi:10.1016/j.conbuildmat.2017.12.149.

[34] D. Ferretti, E. Coïsson, D. Ugolotti, E. Lenticchia, Use of EC6-like equations to estimate the compressive strength of masonry made of solid clay bricks and lime mortar, in: C. Modena, F. da Porto, M.R. Valluzzi (Eds.), Brick Block Mason. - Trends, Innov. Challenges, Taylor \& Francis Group, 2016: p. 1561-1570. 
[35] D. Liberatore, A. Marotta, L. Sorrentino, Estimation of solid clay brick unreinforced masonry compressive strength based on mortar and unit mechanical parameters, in: Proceedings of 9th Int. Mason. Conf., Guimaraes, 2014: p. 1715-1722.

[36] M. Drdácký, Non-Standard Testing of Mechanical Characteristics of Historic Mortars, Int. J. Archit. Herit. 5 (2011) 383-394. doi:10.1080/15583051003717788.

[37] European Committee for Standardization (CEN), EN 1015-11 Methods of test for mortar for masonry - Part 11: Determination of flexural and compressive strength of hardened mortar, (1999).

[38] ACI, ASCE, TMS, Commentary on Specification for Masonry Structures (ACI 530.1-02/ASCE 6-02/TMS 60202), (2004).

[39] European Committee for Standardization (CEN), Eurocode 6: Design of masonry structures - Part 1: General rules for reinforced and unreinforced masonry structures, (2005). 